the original conclusion proves to be correct. The site, though confined to a limited area, has yielded a typical series of developed Aurignacian tools, including long batter-backed blades, keeled scrapers, and burins of various types; also microlithic blades.

The Scunthorpe area has long been known as one of the type stations of the Azilio-Tardenoisian culture in England, and the Upper Aurignacian site forming the subject of this communication is situated within a few miles of one of the areas where pygmy tools are most abundant. The industry represented, however, is free from Tardenoisian influences. Pygmy tools are extremely scarce, and it is believed to be a representative site of the native culture upon which the Azilian and the Tardenoisian was engrafted. Tools which appear to belong to the same cultural epoch have been collected on the ridges southwards towards Lincoln, occurring upon the surface together with tools of later industries, and what is likely to prove a second definite occupation area has now been located in the vicinity of Willoughton and is under examination.

\section{The Rubber Research Institute of Malaya.}

THE annual report of the Rubber Research Institute of Malaya for 1930, covering the fourth year of active operations, shows that in spite of difficulties caused by shortage of staff, very considerable progress has been made. The Soils Division has continued its work on the manuring both of immature and mature rubber, and although the low price of rubber has induced caution in the application of artificial fertilisers, it has been possible to obtain valuable data regarding the effect of nitrogen, and nitrogen and potash together. A paper is to be published shortly, summarising our information on manuring the rubber tree, and the Soils Division is also cooperating with Imperial Chemical Industries, Ltd., and Malayan Fertilisers, Ltd., in similar experiments.

Other work has been concerned with practical methods of soil conservation and particularly the value of cover crops, and there is increasing realisation that the mere growth of a cover is not a universal remedy for trees in poor vegetative growth. Small fertiliser dressings, given individually to the young trees, seem a more economic way of inducing rapid growth without prejudice to future soil fertility.

In spite of the absence of a head of division, the Botanical Division has made considerable progress with its investigations on the improvement of Hevea planting material by vegetative means and on the response of the tree to different methods of tapping. This work, carried on not only at the experimental station but also in co-operation with various estates throughout Malaya, is providing information on the replanting of old areas which are becoming wasting assets through root disease in the old trees, as well as assisting the selection of new elones from high yielding trees or seedlings of known origin. Tapping experiments have indicated the existence of three or four very promising new Malayan clones.

The Chemical Division has continued its work on the separation and characterisation of latex constituents, particularly on the non-caoutchouc constituents which affect so largely the properties of raw and unvulcanised rubber. In addition, investigations have been carried out on the efficiency of sheet manufacture, the drying of crepe and sheet, the cause and elimination of defects in lower grade rubber, and the preservation and concentration of latex. Methods of spectrographic analysis are being developed by the Institute for soil investigations and for such problems as the effect of minute traces of certain metals on the properties of raw rubber.

\section{University and Educational Intelligence.}

Cambridge.-R. J. Pumphrey, of Trinity Hall, has been appointed University demonstrator in the Department of Zoology.

A grant of $£ 125$ has been made from the Balfour Fund to L. C. Beadle, of Pembroke College, for research on the biology of African lakes.

The managers of the Pinsent-Darwin studentship in mental pathology give notice that an election will be made in December. The studentship is of the annual value of not less than $£ 200$, and is tenable for three years. The student must engage in original research into any problem having a bearing on mental defects, diseases, or disorders ; but may carry on educational work concurrently. Applications should be made before Dec. 5 to the Secretary, Pinsent-Darwin Studentship, Psychological Laboratory, Cambridge.

Edinburgh. - The following appointments of lecturers have recently been made:-Mr. E. G. Dymond, in natural philosophy; Dr. E. L. Ince, in mathematics; Dr. R. A. R. Gresson, in zoology (cytology); Dr. Peter Gray, in zoology (vertebrate embryology); Lieut.-Col. S. Hunter Cowan, in forest engineering.

Among the honours approved by the King, arising out of the recent dissolution of parliament, is that conferred upon Sir W. Martin Conway, who has been made a baron. Sir Martin Conway was member of parliament for the Combined English Universities from 1918 until 1931.

The Carnegie Foundation for the Advancement of Teaching has issued its twenty-fifth annual report, for the year ending June 30, 1930. Dr. Henry S. Pritchett, who was associated with Andrew Carnegie in organis ing the Foundation in 1905, presided over its administration from then until August 1930, when he made over charge to Dr. Henry Suzzallo. Starting with an endowment of ten million dollars, the Foundation has grown until its resources now amount to more than thirty-two million, whilst its annual expenditure, chiefly on pensions for University officers and teachers and their widows, is not far short of two millions. Among the topics of outstanding interest dealt with in the president's report is that of American college athletics. Dr. Pritchett exposes the too common exploitation of the student, his diversion from genuine college study and social life, his service under professional trainers in preparation for a commercial show before the public. As an indication of the importance of the rôle football plays in American university finances, he cites the fact that at Harvard the income from athletics (almost wholly from football) is one and a quarter million dollars, as compared with an income of three millions from tuition. In connexion with the study of the relations of secondary and higher education, which is being conducted by the Foundation jointly with the Pennsylvania State Department of Public Instruction, two comprehensive examinations have been administered in some fifty colleges and universities with the special object of measuring effective knowledge as distinguished from raw information. The results indicate that the American system of term courses with term examinations and credits fails lamentably as regards what is supposed to be the central purpose of the college, namely, teaching the student to think. Incidentally, they indicate better mental capacity in students of the sciences than in students of arts subjects. 